\title{
Foods prepared outside the home: association with selected nutrients and body mass index in adult Australians
}

\author{
Cate Burns*, Michelle Jackson, Carl Gibbons and Rachel M Stoney \\ Faculty of Health and Behavioural Sciences, School of Health Sciences, Deakin University, Burwood Campus, 221 \\ Burwood Highway, Burwood, Victoria 3125, Australia
}

Submitted 29 June 2001: Accepted 29 October 2001

\begin{abstract}
Objective: To determine the proportion of energy from foods prepared outside the home $(\mathrm{FPOH})$ and the relationships with energy and nutrient intakes and body mass index (BMI).

Design: A nutrition survey of a representative sample of the Australian population aged 18 years and over $(n=10863)$. Measure used was a 24-hour dietary recall. Underreporters (energy intake/estimated basal metabolic rate (EI/BMR) <0.9) were excluded from analysis. Daily energy and selected nutrient intakes were calculated using a 1996 nutrient composition database for all foods/beverages during the 24-hour period.

Results: On average FPOH contributed a significant 13\% to total energy intake. About a third of the sample had consumed FPOH in the last 24 hours and on average this group consumed a third of their total energy as FPOH. The relative contributions of fat (for men and women) and alcohol (for women) were significantly higher for those in the top tertile of FPOH consumers. The intakes of fibre and selected micronutrients (calcium, iron, zinc, folate and vitamin C) were significantly lower in this group. After adjustment for age and income no relationship between FPOH and BMI was observed.

Conclusions: FPOH make a significant contribution to the energy intake of a third of the Australian population. FPOH contribute to poor nutritional intakes. Altering the supply of FPOH may be an effective means of improving diets at a population level.
\end{abstract}

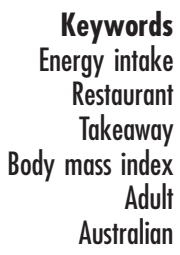

The proportion of foods prepared outside the home $(\mathrm{FPOH})$ has increased in developed countries ${ }^{1-3}$. In the USA, for example, food expenditure at outside eateries increased from 26\% 1970 to 39\% 1996 ${ }^{4}$. In Australia, in 1989, 24.5\% of total expenditure on food was spent on meals out or takeaways 5 . This represents an increase of $6.5 \%$ over the preceding 13 years ${ }^{5,6}$. Although the consumption of foods prepared outside the home has increased, there are limited data about the possible effect of this trend on energy and nutrient intakes, and measures of nutritional status such as relative body weight of adults. Comparisons between countries are made difficult because of different definitions of 'foods prepared and/or consumed outside the home'.

Existing studies on FPOH consumption show a decline in micronutrient intakes with increasing consumption of $\mathrm{FPOH}^{7-10}$. Haines et al. found that the nutrient intakes of US women who obtained $30-50 \%$ of total energy from FPOH were significantly different from those of women who ate the majority of their food at home ${ }^{11}$. Away-fromhome intakes were high in energy, saturated fat, cholesterol and sodium, and low in fibre, calcium, vitamin
$\mathrm{C}$ and folate, but poor dietary intake was only observed in those women consuming greater than 30\% of total energy from $\mathrm{FPOH}^{11}$. In a longitudinal study, Lin et al. showed that foods prepared away from home contributed more total fat and saturated fat and less calcium, fibre and iron than home-prepared foods ${ }^{4}$. This study also showed that while reported fat intake from both sources (home and outside) had declined over the previous 20 years, the fat intake from takeaway foods had declined less ${ }^{4}$.

It has been widely speculated that the increase in obesity observed world-wide is in part due to the increased use of $\mathrm{FPOH}^{12}$, with a relationship between takeaway foods and relative body weight being described in several small studies ${ }^{13-15}$. More recently, using data from the Continuing Survey of Food Intakes by Individuals (CSFII), Binkley et al. ${ }^{16}$ found a significant relationship between eating at restaurants and body mass index (BMI) in men and fast food consumption and BMI in men and women.

The studies of the impact of FPOH on nutrient intakes and body weight are largely US-based. There is a need for data from other countries where different cultural and 
economic factors may cause variation in the use of $\mathrm{FPOH}$. It is likely that, in future, even more of the preparation of food - either partial or complete - will occur outside the home $^{17}$. It is important to understand how the consumption of FPOH affects energy and nutrient intakes. Previous findings need to be replicated in different populations and cultures. This will enable public health policy or education programmes to be directed more effectively.

The aim of the current study was to determine the proportion of energy intake from $\mathrm{FPOH}$ and its relationship with BMI, energy and nutrient intakes in a nationally representative sample of Australian adults.

\section{Methods}

\section{Sample}

This study used confidentialised unit record file (CURF) data collected from the 1995 National Nutrition Survey $(\text { NNS95 })^{18}$. This survey was conducted on a sub-sample of participants from the 1995 National Health Survey $(\mathrm{NHS})^{19}$. The NHS interviewed a total of 57633 persons, of whom 22562 persons were selected to be interviewed for the NNS95. Sixty per cent of those selected as potential subjects participated in the NNS95. This is not an unusual response rate for a population-based survey. The final respondent sample for the NNS95 was 13858. For the purpose of the present paper, the data were restricted to adult males and females who were defined as being aged 18 years and over $(n=10863)$.

In order to minimise the effect of dietary underreporting $^{20}$, participants' reported energy intake was assessed in relation to their estimated basal metabolic rate (BMR) in accordance with the guidelines set out by Goldberg et $a l .{ }^{21}$ for dietary assessment. BMR was derived from measured weight using the age- and sex-specific equations of Schofield ${ }^{22}$. Subjects with an energy intaketo-BMR ratio (EI/BMR) of less than or equal to 0.9 were excluded. This cut-off, recommended by Goldberg et al. ${ }^{21}$, represents the lower 95\% confidence limit for a plausible level of energy intake relative to estimated BMR for 1-day intake data and an estimated energy expenditure level of $1.55 \times$ BMR. Using this cut-off criterion, 635 (14\%) males and 1400 (32\%) females were removed, leaving a final sample size of 8828 .

\section{Assessment of dietary intake}

Food and nutrient intakes were assessed by a multiplepass 24-hour dietary recall, based on the methodology used by the Agriculture Research Service of the United States' Department of Agriculture for the CSFII 1994$96^{23,24}$. Information was collected on all foods and beverages consumed from midnight to midnight on the day before the interview ${ }^{18}$.

\section{Definition offoods prepared outside the bome (FPOH)}

For each of the foods reported in the 24-hour dietary recall, the place where the food was obtained was categorised according to a pre-defined list of sources ${ }^{18}$. There were 15 food source categories; a complete category list is given in the Appendix. The major sources of all food eaten were shop (74.5\%), restaurant/café/ cafeteria/takeaway/pizza/fast food place (9\%), someone else/gift (6.4\%), bar/tavern/hotel/club/pub (2\%), workplace $(2.7 \%)$. For the current analysis, foods prepared outside the home were defined as those sourced from restaurants, cafés, cafeterias and takeaway/pizza/fast food places irrespective of place of consumption. This definition was most consistent with that used in previous reports $^{1-4}$.

Energy and nutrient intake values used for the present analysis were those provided in the NNS95 CURF, which were calculated from the nutrient composition database developed by the Australian and New Zealand Food Authority $^{25}$ for all foods/beverages during the 24-hour period for the NNS95. The proportion of energy from FPOH was determined by expressing the energy from FPOH as a percentage of the total energy intake. For some analyses the sample was divided into tertiles of energy intake from $\mathrm{FPOH}$. The foods making the greatest contribution to reported energy intake were determined by selecting the 20 foods making the largest cumulative contribution to total energy intake.

\section{Demographic variables}

\section{Age}

For the current analysis, an estimated age variable was created by setting each subject's age to the mid-point of his/her five-year age range. Subsequently, four broad age categories were established for use in the summary tables: 18-24 years, 25-49 years, 50-74 years and 75+ years.

\section{Housebold income}

Highest household income was given as the personal income of the highest-earning individual within each household. The NHS recorded income in $\$ 5000$ categorical ranges. For the purposes of the present study, an estimated dollar-value for this variable was developed by obtaining the mid-point of each range.

\section{Socio-economic index for areas (SEIFA)}

The SEIFA index used in the NNS is an index of relative social disadvantage that describes the characteristics of the area in which a person lives, rather than the characteristics of the person ${ }^{19}$. The SEIFA index of social disadvantage assigns an index to geographical areas based on socioeconomic variables such as economic resources, education and occupation. People in the first quintile 
live in the most disadvantaged areas whereas those in the fifth quintile live in the least disadvantaged areas.

\section{Housebold size}

A household was defined as a person or persons residing within a dwelling who make provision for their own food supply and life essentials. For the current study, household size was reported in three categories: one person, two persons and more than two persons.

\section{Country of birth}

The country of birth was grouped as follows: Australasia (Australia and New Zealand), UK and Ireland, Europe and Middle East, Asia and Other (North American, South American, Central America and the Caribbean, Africa).

\section{Body mass index (BMI)}

BMI was derived from weight and height measured to the nearest $0.1 \mathrm{~kg}$ and $0.1 \mathrm{~cm}$, respectively, according to standard procedures ${ }^{18}$. BMI was classified using World Health Organization (WHO) definitions ${ }^{26}$ : underweight or thinness $\left(<18.5 \mathrm{~kg} \mathrm{~m}^{-2}\right)$; normal or acceptable weight (18.5-<25 $\left.\mathrm{kg} \mathrm{m}^{-2}\right)$; overweight $\left(25-<30 \mathrm{~kg} \mathrm{~m}^{-2}\right)$; and obese $\left(>30 \mathrm{~kg} \mathrm{~m}^{-2}\right)$.

\section{Statistical analyses}

Statistical analyses were carried out, separately for men and women, using STATA version 6.0 and SPSS version 9.0. Results are given as mean \pm standard deviation (SD) unless otherwise stated. Analysis of variance (ANOVA) was used to assess differences in the proportion of energy intake from $\mathrm{FPOH}$ for the following variables: age, income, SEIFA and number of people in household. The relationship between BMI and percentage of energy from FPOH intake was determined by ANOVA with adjustment for age and income. Student $t$-tests with Scheffe's post hoc tests were used to test for differences in the continuous variables, and in demographics. ANOVA adjusted for covariates - gender, age and income - was used to assess the relationship between tertiles of $\mathrm{FPOH}$ intake and energy and nutrient intakes. Relative contribution to energy intake by specific food groups was determined directly from the NNS dataset and the top 10 contributing foods are reported here.

\section{Results}

\section{Description of sample}

Table 1 shows the distribution of demographic characteristics of the survey participants considered for this study. The distribution of the study sample was consistent with Australian Bureau of Statistics (ABS) data ${ }^{27}$ for age, household income and country of birth. This finding was consistent with previous findings for men (1989-1990) and higher than previous figures for women (64\%) from the 1989-1990 National Health Survey ${ }^{28}$. Forty-four per
Table 1 Demographics of the study population

\begin{tabular}{|c|c|c|c|}
\hline & \multicolumn{3}{|c|}{ Number (percentage of sample) } \\
\hline & Male & Female & Total \\
\hline \multicolumn{4}{|l|}{ Age category } \\
\hline $18-24$ years & $501(10)$ & $496(10)$ & $997(11)$ \\
\hline $25-49$ years & $2296(52)$ & $2213(51)$ & 4509 (52) \\
\hline $50-74$ years & $1449(33)$ & $1396(32)$ & $2845(32)$ \\
\hline $75+$ years & $211(5)$ & $266(6)$ & $477(5)$ \\
\hline \multicolumn{4}{|l|}{ BMI } \\
\hline Underweight & $31(1)$ & $116(3)$ & $147(2)$ \\
\hline Acceptable weight & $1618(36)$ & $2278(52)$ & $3896(44)$ \\
\hline Overweight & $2058(46)$ & $1311(30)$ & 3369 (38) \\
\hline Obese & $750(17)$ & $666(15)$ & $1416(16)$ \\
\hline \multicolumn{4}{|l|}{ Household income } \\
\hline$\leq \$ 12500$ & $1085(28)$ & $1480(39)$ & $2565(33)$ \\
\hline$\$ 12501-32500$ & $1559(40)$ & $1454(39)$ & $3013(39)$ \\
\hline$\$ 32501-42500$ & $564(14)$ & $410(11)$ & 974 (13) \\
\hline$\$ 42501-52500$ & $298(8)$ & $195(5)$ & $493(6)$ \\
\hline$\$ 52501-62500$ & $157(4)$ & $79(2)$ & $236(3)$ \\
\hline$\$ 62501-72500$ & $65(2)$ & $44(1)$ & $109(2)$ \\
\hline$\$ 72501+$ & $172(4)$ & $108(3)$ & $280(4)$ \\
\hline \multicolumn{4}{|c|}{ Number of people in household } \\
\hline Single person & $580(13)$ & $651(15)$ & $1231(14)$ \\
\hline Two persons & $1878(42)$ & $1882(43)$ & $3760(43)$ \\
\hline More than two persons & 1999 (45) & $1838(42)$ & $3837(43)$ \\
\hline \multicolumn{4}{|l|}{ Region of birth } \\
\hline Australia \& New Zealand & $3420(76)$ & $3318(76)$ & $6738(76)$ \\
\hline UK \& Ireland & $473(11)$ & $481(11)$ & $954(11)$ \\
\hline Europe \& Middle East & $302(7)$ & $284(6)$ & $586(7)$ \\
\hline Asia & $143(3)$ & 177 (4) & $320(3)$ \\
\hline Other & $119(3)$ & 111 (3) & $230(3)$ \\
\hline
\end{tabular}

Low energy reporters not included in the sample demographics.

cent were in the 'acceptable weight' and 54\% in the 'overweight' and 'obese' categories. Prevalence of overweight had increased from previous national surveys ${ }^{29}$.

There were 635 (14\%) men and 1400 (32\%) women classified as low energy reporters. Male low energy reporters were more likely to be older $\left(\chi^{2}=19.2\right.$, $P=0.0)$, overweight or obese $\left(\chi^{2}=185.0, P=0.00\right)$, to have a higher income $\left(\chi^{2}=14.65, P<0.023\right)$ and to live alone $\left(\chi^{2}=16.62, P=0.00\right)$. Female low energy reporters were more likely to be overweight or obese $\left(\chi^{2}=276.02\right.$, $P=0.00)$ and have a higher household income $\left(\chi^{2}=15.03, P<0.02\right)$.

\section{Consumption of FPOH}

Thirty-six per cent $(n=3150)$ of the total sample had consumed some FPOH in the last 24 hours. For the total population, the average percentage of energy intake from FPOH in the previous 24 hours was $12.9 \pm 22.0 \%$ for women and $13.5 \pm 21.7 \%$ for men. Seventy per cent of the total energy intake for both men $(70.1 \pm 27.6 \%)$ and women $(72.8 \pm 27.6 \%)$ was obtained from a shop (including a supermarket). For those who had consumed FPOH in the last 24 hours, the average contribution of FPOH to total daily energy intake was $36.2 \pm 21.8 \%$. 


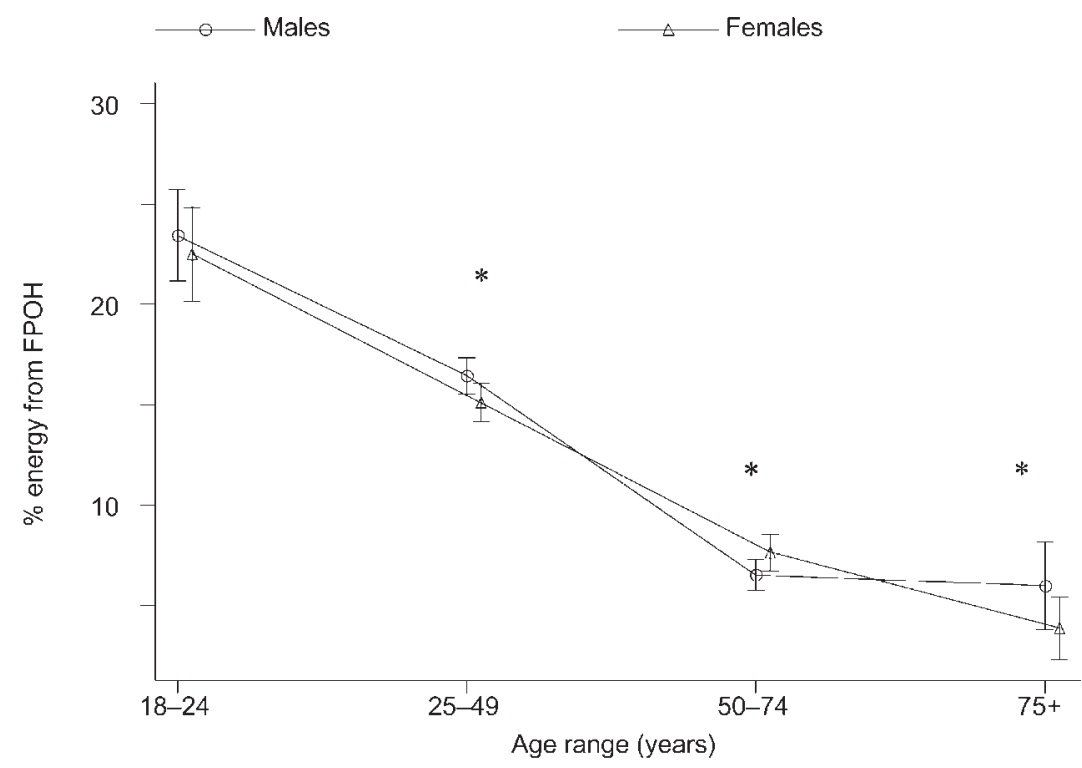

Fig. 1 Relationship between \% energy from FPOH and age range in males and females (* indicates significant difference, $P<0.001$, against age range 18-24 years for males and females)

\section{Percentage of energy from FPOH and population characteristics}

Figure 1 shows the percentage of energy from FPOH relative to age. Young men and women (18 to 24 years) had the highest energy intake from FPOH $(23 \pm 26 \%)$. A higher income was associated with increased energy intake from foods prepared away from home (Fig. 2). There was no difference in energy intake from $\mathrm{FPOH}$ when the sample was divided on the basis of the index of relative socio-economic disadvantage. Household size was positively associated with energy intake from $\mathrm{FPOH}$ in women but not men. Australasian men $(14.1 \pm 22 \%)$ and men of Asian origin (17.3 $\pm 25 \%)$ had a higher consumption of $\mathrm{FPOH}$ than European and Middle Eastern men
$(8 \pm 17 \%)(P<0.001)$. When the population was divided relative to the WHO (1995) standard for body weight, the differences in relative energy intake from $\mathrm{FPOH}$ were large, particularly in men. However, the observed association with BMI was nearly completely removed after adjustment for age and income. Table 2 shows adjusted and unadjusted percentage of energy from $\mathrm{FPOH}$ for BMI group and sex.

\section{Percentage of energy from FPOH and macro- and micronutrient intakes}

Those subjects who had consumed FPOH in the last 24 hours were divided into tertiles for energy consumption from $\mathrm{FPOH}$, and subjects in the tertiles of energy intake

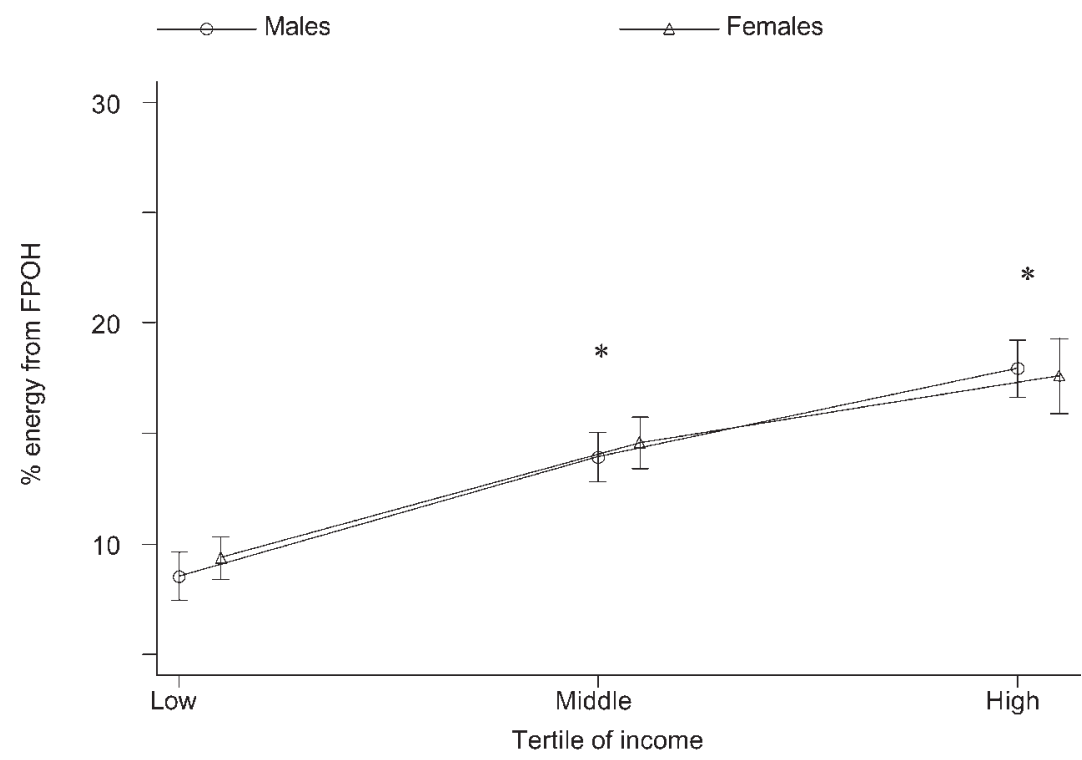

Fig. 2 Relationship of \% energy form $\mathrm{FPOH}$ and income tertile in males and females ( ${ }^{*}$ indicates significant difference, $P<0.001$, against lowest tertile of income for males and females) 
Table 2 Unadjusted \% energy from $\mathrm{FPOH}$, plus age- and income-adjusted \% energy from $\mathrm{FPOH}$ by BMI category and sex $(n=8828)$

\begin{tabular}{llc}
\hline & \multicolumn{2}{c}{$\begin{array}{c}\text { \% energy from FPOH, } \\
\text { mean (SD) }\end{array}$} \\
\cline { 2 - 3 } & Unadjusted & Adjusted \\
\hline Men & $22.28(29.5)^{\star}$ & $16.3(24.7)$ \\
$\quad$ Underweight & $14.85(22.6)$ & $13.6(21.8)$ \\
Acceptable weight & $12.84(21.1)$ & $13.1(20.1)$ \\
Overweight & $12.03(20.5)$ & $13.5(20.5)$ \\
Obese & & \\
Women & $15.17(25.5)$ & $14.2(25.6)$ \\
Underweight & $13.53(22.2)$ & $12.8(21.7)$ \\
Acceptable weight & $11.65(214)$ & $14.1(20.9)$ \\
$\quad$ Overweight & $12.62(21.9)$ & $15.2(21.1)$ \\
Obese &
\end{tabular}

${ }^{*} P<0.05$ significant difference between BMI categories by ANOVA.

from FPOH were compared with subjects who had not consumed FPOH in the last 24 hours (Table 3). The energy and nutrient analyses were adjusted for the covariates: energy intake, age and income. Total energy, macro- and micronutrient intakes were compared between the four groups (Table 3). Subjects who had not eaten any FPOH had a significantly lower energy intake than subjects who had consumed FPOH. Both men and women in the upper tertile for $\mathrm{FPOH}$ consumption had higher intakes of saturated fat, absolute fat and energy as fat, and lower intakes of calcium, iron, zinc, folate and vitamin C (Table 3). These effects were similar with or without adjustment for age and income.

\section{Foods contributing to energy intake for consumers and non-consumers of $\mathrm{FPOH}$}

Energy-contributing foods unique to those with the highest energy intake from $\mathrm{FPOH}$ were filled rolls and hamburgers, pizza, poultry or game, crumbed, battered, meatloaf or patty type with cereal. Table 4 gives the top 10 energy-contributing foods prepared outside the home. Potatoes (potatoes, potato products and potato dishes) made the largest contribution (15\%), followed by filled rolls and hamburgers (7\%) and pizza (6\%).

\section{Discussion}

The current study was of the National Nutrition Survey 1995, a dataset of 10800 adult Australians. Analysis of the dataset was focused on the dietary consequences of the consumption of FPOH. On average, FPOH made a significant contribution to energy intake (13\%) for both men and women. This figure is comparable with figures from the $\mathrm{USA}^{16}$. Thirty per cent of the sample had consumed FPOH in the last 24 hours and, on average, these people consumed a third of their total energy as FPOH. Again, these figures are comparable with data from the USA ${ }^{16}$. Younger men and women had a higher energy intake from $\mathrm{FPOH}$ than older men and women.
Consumption of FPOH also increased with income but not with household size. Men, particularly of Asian origin, had a higher intake of FPOH. The relative contributions of fat (for men and women) and alcohol (for women) to total energy intake were significantly higher in the upper tertile of FPOH consumption, while the intakes of fibre and micronutrients (calcium, iron, zinc, folate, vitamin C) were significantly lower in this group.

In the current study, the differences in nutrient intake between $\mathrm{FPOH}$ consumers and non-consumers were small. However, calculation of attributable risk for dietary factors in lifestyle diseases is difficult and the effect likely to be small because many of these diseases are multifactorial and develop cumulatively over a lifetime. The burden or benefit in public health terms will be a product of these small changes, adopted by a large number of people, to give large absolute changes in diet and health. Thus a health benefit can be achieved to a population's disease burden with small changes in diet that may not be of clinical significance to the individual.

In our dataset, the mean difference in fat intake between FPOH non-consumers and high FPOH consumers was $0.5 \mathrm{~g} \mathrm{MJ}^{-1}$ (1.6\% energy from fat). Given an equivalent level of energy expenditure between consumers and nonconsumers, this would put FPOH consumers in energy imbalance of $3 \mathrm{~g}$ fat per week. This amounts to $150 \mathrm{~g}$ of dietary fat per year. This is energetically equivalent to $30 \%$ of the individual weight gain observed in Australia between 1989/90 and 1994/95 ${ }^{28,29}$. This amount of weight gain is not trivial. The size of the differences observed in our dataset is corroborated by other studies of $\mathrm{FPOH}$, fat intake and $\mathrm{BMI}^{14-16}$.

The effect of consumption of FPOH on nutrient intakes has been previously reported ${ }^{2-11}$. Intake of $\mathrm{FPOH}$ is associated with lower intakes of fat - both total and saturated - and poor intakes of fibre, calcium and vitamins $\mathrm{A}, \mathrm{B}_{6}$ and $\mathrm{C}$. The effect is, however, 'dose-dependent'. A number of groups ${ }^{10,11}$ have demonstrated that nutritional risk is only high in those with high consumption of $\mathrm{FPOH}$. Haines and colleagues ${ }^{11}$ have demonstrated a high risk of nutritional inadequacy in women with approximately $70 \%$ of food energy purchased from fast food or restaurants. Our results are consistent with those from other population studies that have shown an effect on energy and nutrient intakes of excessive consumption of FPOH.

A crude comparison of data from the 1983 and 1995 national nutrition surveys ${ }^{30-33}$ shows that consumption of the takeaway component of FPOH (fried foods, hamburgers, meat pies and sausage rolls) has doubled over that period, from 39 to $70 \mathrm{~g} \mathrm{day}^{-1}$ in men and from 14 to $36.8 \mathrm{~g}$ day $^{-1}$ in women. Some of this difference may be due to different classification of foods but there is a clear trend. This is interesting given that total energy intake has stayed the same and intake of fat as a percentage of total energy has dropped (from 37 to $32 \%$ in both men and women). Broadly speaking it would appear that consumption of 
Table 3 Mean (SD) energy intake and nutrient intakes (adjusted for energy intake, age and income) in men and women who consumed no FPOH in the previous 24 hours compared with tertiles of men and women who consumed FPOH

\begin{tabular}{|c|c|c|c|c|c|c|}
\hline & None & First tertile & Second tertile & Third tertile & & $\begin{array}{l}\text { lain } \\
\text { fect }\end{array}$ \\
\hline \multicolumn{7}{|l|}{ Men } \\
\hline$\%$ energy from $\mathrm{FPOH}$ & 0 & $14.1(6.8)$ & $33.4(5.5)$ & $61.0(14.0)$ & & \\
\hline Energy intake (MJ) & 113979 (3399.3) & $12377(4092.4)$ & 12095.5 (3639.3) & $12276.3(4326.1)$ & * & $a b c$ \\
\hline Protein $\left(\mathrm{g} \mathrm{MJ}^{-1}\right)$ & $9.9(2.6)$ & $9.8(2.7)$ & $9.7(2.6)$ & $9.8(2.7)$ & & \\
\hline Fat $\left(\mathrm{g} \mathrm{MJ}^{-1}\right)$ & $8.7(2.2)$ & $8.7(2.1)$ & $8.9(2)$ & $9.2(1.9)$ & * & ce \\
\hline Saturated fat $\left(\mathrm{g} \mathrm{MJ}^{-1}\right)$ & $3.4(1.3)$ & $3.5(1.2)$ & $3.6(1)$ & $3.6(1.1)$ & * & $c$ \\
\hline Monounsaturated fat $\left(\mathrm{g} \mathrm{MJ}^{-1}\right)$ & $3.2(1)$ & $3.1(0.9)$ & $3.3(0.9)$ & $3.4(0.8)$ & * & ce \\
\hline Polyunsaturated fat $\left(\mathrm{g} \mathrm{MJ}^{-1}\right)^{\prime}$ & $1.3(0.6)$ & $1.3(0.6)$ & $1.3(0.6)$ & $1.4(0.5)$ & & \\
\hline Cholesterol $\left(\mathrm{g} \mathrm{MJ}^{-1}\right)$ & $31.6(19.9)$ & $30.9(15.8)$ & $31.4(17.6)$ & $34.9(15.7)$ & * & cef \\
\hline Carbohydrate $\left(\mathrm{g} \mathrm{MJ}^{-1}\right)$ & $27.4(6.2)$ & $27.5(6)$ & $27.3(5.5)$ & $26.7(5.3)$ & & \\
\hline Sugar $\left(\mathrm{g} \mathrm{MJ}^{-1}\right)$ & $12.3(5.6)$ & $12.4(5.7)$ & $12.3(5)$ & $12(5.4)$ & & \\
\hline Starch $\left(\mathrm{g} \mathrm{MJ}^{-1}\right)$ & $14.9(4.6)$ & $14.9(4.8)$ & $14.9(4.3)$ & $14.5(4.3)$ & & \\
\hline Fibre $\left(\mathrm{g} \mathrm{MJ}^{-1}\right)^{\prime}$ & $2.5(1.1)$ & $2.4(1)$ & $2.3(0.9)$ & $2.1(0.8)$ & * & bce \\
\hline Alcohol $\left(\mathrm{g} \mathrm{MJ}^{-1}\right)$ & $1.8(2.9)$ & $1.8(2.8)$ & $1.7(2.8)$ & $1.7(2.4)$ & & \\
\hline Calcium (mg MJ $\left.{ }^{-1}\right)$ & $88(41)$ & $89.2(46.2)$ & $86.8(37.4)$ & $81(37.1)$ & * & ce \\
\hline Iron $\left(\mathrm{mg} \mathrm{MJ}^{-1}\right)$ & $1.5(0.5)$ & $1.5(0.5)$ & $1.5(0.5)$ & $1.4(0.5)$ & * & cef \\
\hline $\operatorname{Zinc}\left(\mathrm{mg} \mathrm{MJ}^{-1}\right)$ & $1.3(0.5)$ & $1.3(0.9)$ & $1.3(0.6)$ & $1.3(1.3)$ & & \\
\hline Folate $\left(\mathrm{mg} \mathrm{MJ}^{-1}\right)$ & $29.4(11.7)$ & $28.1(10.6)$ & $27(9)$ & $25.7(8.8)$ & * & bce \\
\hline Thiamine $\left(\mathrm{mg} \mathrm{MJ}^{-1}\right)$ & $0.2(0.1)$ & $0.2(0.1)$ & $0.2(0.1)$ & $0.2(0.1)$ & & \\
\hline Vitamin $\mathrm{C}\left(\mathrm{mg} \mathrm{MJ}^{-1}\right)$ & $13.3(10.7)$ & $11.5(10.1)$ & $11.6(10.6)$ & $11.1(11)$ & * & $a b c$ \\
\hline$\%$ of daily energy from fat & $32.3(8.2)$ & $32.3(7.8)$ & $33.1(7.5)$ & $33.9(7.1)$ & * & $\mathrm{ce}$ \\
\hline$\%$ of daily energy from carbohydrates & $43.9(9.9)$ & $44(9.5)$ & $43.7(8.9)$ & $42.6(8.5)$ & & \\
\hline$\%$ of daily energy from protein & $16.8(4.5)$ & $16.6(4.7)$ & $16.5(4.4)$ & $16.7(4.5)$ & & \\
\hline$\%$ of daily energy from alcohol & $5.1(8.5)$ & $5.4(8)$ & $4.9(8)$ & $4.9(6.9)$ & & \\
\hline \multicolumn{7}{|l|}{ Women } \\
\hline$\%$ energy from $\mathrm{FPOH}$ & 0 & $13.5(6.8)$ & $33.2(5.7)$ & $61.9(14.5)$ & & \\
\hline Energy intake (MJ) & 8301.7 (2339.3) & $8750.6(2834.6)$ & $8295.8(2579.1)$ & 8614.5 (3091.8) & * & a \\
\hline Protein $\left(\mathrm{g} \mathrm{MJ}^{-1}\right)$ & $10(2.6)$ & $9.8(2.8)$ & $9.7(2.7)$ & $9.5(2.7)$ & * & $c$ \\
\hline Fat $\left(\mathrm{g} \mathrm{MJ}^{-1}\right)$ & $8.9(2.3)$ & $9.2(2.3)$ & $9.2(1.9)$ & $9.4(2)$ & * & $b c$ \\
\hline Saturated fat $\left(\mathrm{g} \mathrm{MJ}^{-1}\right)$ & $3.5(1.3)$ & $3.7(1.3)$ & $3.7(1.1)$ & $3.8(1.2)$ & * & $c$ \\
\hline Monounsaturated fat $\left(\mathrm{g} \mathrm{MJ}^{-1}\right)$ & $3.2(1)$ & $3.3(1.1)$ & $3.3(0.9)$ & $3.4(0.8)$ & * & $c$ \\
\hline Polyunsaturated fat $\left(\mathrm{g} \mathrm{MJ}^{-1}\right)^{\prime}$ & $1.4(0.7)$ & $1.4(0.6)$ & $1.4(0.6)$ & $1.4(0.6)$ & & \\
\hline Cholesterol $\left(\mathrm{g} \mathrm{MJ}^{-1}\right)$ & $31.2(20.9)$ & $30.8(16.9)$ & $32.3(18.3)$ & $35.1(19.2)$ & * & $\mathrm{ce}$ \\
\hline Carbohydrate $\left(\mathrm{g} \mathrm{MJ}^{-1}\right)$ & $28.3(5.9)$ & $27.7(5.8)$ & $27.9(5.2)$ & $27.3(5.5)$ & * & C \\
\hline Sugar $\left(\mathrm{g} \mathrm{MJ}^{-1}\right)$ & $13.1(5.3)$ & $13.1(5.3)$ & $12.9(5.2)$ & $12.6(5.4)$ & & \\
\hline Starch $\left(\mathrm{g} \mathrm{MJ}^{-1}\right)$ & $15(4.8)$ & $14.5(4.7)$ & $14.8(4.3)$ & $14.6(4.6)$ & & \\
\hline Fibre $\left(\mathrm{g} \mathrm{MJ}^{-1}\right)^{\prime}$ & $2.9(1.1)$ & $2.7(1.1)$ & $2.6(0.9)$ & $2.3(0.8)$ & * & bcef \\
\hline Alcohol† $\left(\mathrm{g} \mathrm{MJ}^{-1}\right)$ & $1(2.1)$ & $1.1(2.2)$ & $1(2.1)$ & $1.2(2.3)$ & & \\
\hline Calcium ( $\mathrm{mg} \mathrm{MJ}^{-1}$ ) & $104.3(47)$ & $97.4(45.1)$ & $98.7(43.4)$ & $90.1(40.9)$ & * & acf \\
\hline Iron $\left(\mathrm{mg} \mathrm{MJ}^{-1}\right)$ & $1.6(0.5)$ & $1.6(0.5)$ & $1.6(0.5)$ & $1.4(0.5)$ & * & bcef \\
\hline Zinc ( $\left.\mathrm{mg} \mathrm{MJ}^{-1}\right)$ & $1.3(0.5)$ & $1.3(0.5)$ & $1.3(0.9)$ & $1.2(0.9)$ & * & $c$ \\
\hline Folate $\left(\mathrm{mg} \mathrm{MJ}^{-1}\right)$ & $31.7(13.9)$ & $30.1(11.9)$ & $29.2(10.5)$ & $27.4(9.4)$ & * & bce \\
\hline Thiamine $\left(\mathrm{mg} \mathrm{MJ}^{-1}\right)$ & $0.2(0.1)$ & $0.2(0.1)$ & $0.2(0.1)$ & $0.2(0.1)$ & & \\
\hline Vitamin $\mathrm{C}\left(\mathrm{mg} \mathrm{MJ}^{-1}\right)$ & $15.7(13.4)$ & $15(12)$ & $13.9(11.9)$ & $13.5(13.1)$ & * & $b c$ \\
\hline$\%$ of daily energy from fat & $32.9(8.4)$ & $34(8.5)$ & $34.1(7.1)$ & $34.9(7.5)$ & * & $b c$ \\
\hline$\%$ of daily energy from carbohydrates & $45.3(9.4)$ & $44.4(9.3)$ & $44.6(8.4)$ & $43.6(8.8)$ & * & $c$ \\
\hline$\%$ of daily energy from protein & $17(4.5)$ & $16.6(4.8)$ & $16.5(4.6)$ & $16.2(4.5)$ & * & $c$ \\
\hline$\%$ of daily energy from alcohol & $2.8(6.2)$ & $3.1(6.3)$ & $2.9(6.2)$ & $3.5(6.8)$ & * & $c$ \\
\hline
\end{tabular}

${ }^{*} P<0.05$ main effect, ANOVA.

$\dagger$ Alcohol intake averages calculated on valid cases only.

$a, P<0.05$ in post hoc comparison of None to First tertile; $b, P<0.05$ in post hoc comparison of None to Second tertile; $c, P<0.05$ in post hoc comparison of None to Third tertile; $d, P<0.05$ in post hoc comparison of First tertile to Second tertile; $e, P<0.05$ in post hoc comparison of First tertile to Third tertile; $f, P<0.05$ in post hoc comparison of Second tertile to Third tertile.

certain food groups (fruit, vegetables) has been displaced by others (grain foods, takeaway and non-alcoholic drinks). Our data indicate that the major takeaway foods are hot chips, filled rolls, hamburgers and pizza.

The dietary methodology used in the NNS95 (24-hour recall) gives an underestimate of dietary intake and relative energy intake from $\mathrm{FPOH}$. Using this method was not possible to characterise individuals in terms of the contribution of $\mathrm{FPOH}$ to their diets in the longer term and to relate this to a measure of nutritional status such as BMI.
Individuals were therefore categorised according to BMI and the proportion of $\mathrm{FPOH}$ compared between BMI groups. A statistically significant relationship between $\mathrm{FPOH}$ and BMI was observed only in men. FPOH consumption was highest in young men, among whom overweight is less common. These findings could be confounded by dieting or social desirability bias and selective underreporting of high-fat foods in women. The statistical power of this analysis was weakened by the exclusion of 2035 underreporters, many of whom were 
Table 4 Top $10 \mathrm{FPOH}$ according to their contribution to energy intake

\begin{tabular}{lc}
\hline Food item & $\begin{array}{c}\text { \%nergy } \\
\text { contributed }\end{array}$ \\
\hline Potatoes & 15 \\
Filled rolls and hamburgers & 7 \\
Pizza & 6 \\
Savoury pastry products, double crust - pies, rolls and envelopes & 5 \\
Chicken & 5 \\
Poultry and game, crumbed, battered, meatloaf or patty type with cereal & 3 \\
Savoury rice-based dishes & 3 \\
Cheese, natural, traditional & 3 \\
Poultry or game stew, casserole, stir fry with gravy or sauce only & 2 \\
Milk, flavoured and milk-based drinks, full-fat & 2 \\
\hline
\end{tabular}

obese. Jeffrey and French ${ }^{14}$ have previously shown an association with fast food meals per week in women with low socio-economic status but not in men. McCrory et al. ${ }^{15}$ showed a strong association between body fat and frequency of consuming fast foods adjusted for activity level $(r=0.42, P=0.004)$. These strong associations were found in small and select populations using behavioural markers of consumption. One larger study has demonstrated a relationship between fast food and obesity in both men and women in the USA ${ }^{16}$. Further studies are indicated. Using the 24-hour recall we can get only a snapshot of the nation's diet. To explore the relationship between BMI and takeaway foods more detailed studies on both an environmental (outlets per head of population, outlets per square $\mathrm{km}$ ) and an individual basis must be carried out in populations identified as being at risk.

Our data show that high intake of FPOH does have a detrimental impact on energy and nutrient intakes. They also indicate that FPOH consumption is high in young men and women with higher income. In this population FPOH could be targeted by educational or environmental intervention to prevent obesity.

\section{Acknowledgements}

We would like to acknowledge Professor Damien Jolley, Professor Boyd Swinburn and Ingrid Coles for their help in the review of this manuscript and the presentation of the data.

\section{References}

1 Guilkey DK, Haines PS, Popkin BM. The distribution of food consumption over a year: a longitudinal analysis. Am. J. Agric. Econ. 1990; 72: 891-900.

2 Horton S, Campbell C. Wife's employment, food expenditure and apparent nutrient intake: evidence from Canada. Am. J. Agric. Econ. 1991; 73: 784-94.

3 Shrapnel BIS. Fast Food in Australia 1995. Shrapnel BIS, Sydney, 1995.

4 Lin BH, Frazao E, Guthrie J. Away From Home Foods Increasingly Important to the Quality of the American Diet. Agriculture Information Bulletin No. 749. Washington, DC:
United States Department of Agriculture, Economic Research Service, 1999.

5 Australian Bureau of Statistics (ABS). 1993-1994 Household Expenditure Survey. ABS Catalogue No. 6535.0. Canberra: ABS, 1995.

6 Australian Bureau of Statistics (ABS). 1975- 1976 Household Expenditure Survey. Canberra: ABS, 1978.

7 DeCastro JM, Brewer EM, Elmore DK, Orozco S. Social facilitation of the spontaneous meal size of humans occurs regardless of time, place, alcohol or snacks. Appetite 1990; 15: 89-101.

8 Guenther PM, Ricart G. Effect of eating at food service establishments on the nutritional quality of women's diets. Top. Clin. Nutr. 1989; 4: 41-5.

9 Francois P, Calamassi-Tran G, Hebel P, Renault C, Lebreton S, Volatier JL. Food and nutrient intake outside the home of 629 French people of fifteen years and over. Eur. J. Clin. Nutr. 1996; 50: 826-31.

10 Clemens LH, Slawson DL, Kleges RC. The effect of eating out on quality of diet in premenopausal women. J. Am. Diet. Assoc. 1999; 99(4): 442-4.

11 Haines PS, Hungerford DW, Popkin BM, Guilkey DK. Eating patterns and energy and nutrient intakes of US women. J. Am. Diet. Assoc. 1992; 92: 698-704, 707.

12 World Health Organization (WHO). Obesity: Preventing and Managing the Global Epidemic. Report of a WHO Consultation on Obesity, 3-5 June 1997. Geneva: WHO, 1998.

13 Shah M, French SA, Jeffrey RW, McGovern PG, Forster JL, Lando HA. Correlates for high fat/calorie food intake in a worksite population: The Healthy Worker Project. Addict. Behav. 1993; 18: 583-94.

14 Jeffrey R, French SA. Epidemic obesity in the United States: are fast foods and television viewing contributing? $\mathrm{Am}$. J. Public Health 1998; 88: 277-80.

15 McCrory M, Fuss PJ, Hays NP, Vinken AG, Greenberg AS, Roberts SB. Overeating in America: association between restaurant food consumption and body fatness in healthy men and women aged 19 to 80. Obes. Res. 1999; 7: 564-71.

16 Binkley JK, Eales J, Jekanowski M. The relation between dietary change and rising US obesity. Int. J. Obes. 2000; 42: 1032-9.

17 Warde A. Convenience food: space and timing. Br. Food J. 1999; 101: 518-27.

18 Australian Bureau of Statistics (ABS). National Nutrition Survey: User's Guide, Australia, 1995. ABS Catalogue No. 4801.0. Canberra: ABS, 1998.

19 Australian Bureau of Statistics (ABS). National Health Survey: Users' Guide, Australia, 1995. ABS Catalogue No. 4363.0. Canberra: ABS, 1996.

20 Braam LA, Ocke M, Bueno-de-Mesquita HB, Seidell J. Determinants of obesity related under-reporting of energy intake. Am. J. Epidemiol. 1998; 147(11): 1081-6.

21 Goldberg GR, Black AE, Jebb SA, Cole TJ, Murgatroyd PR, 
Coward WA, Prentice AM. Critical evaluation of energy intake data using fundamental principles of energy physiology; derivation of cut-off limits to identify under recording. Eur. J. Clin. Nutr. 1991; 45: 569-81.

22 Schofield WN. Predicting basal metabolic rate, new standards and review of previous work. Hum. Nutr. Clin. Nutr. 1985; 39C(Suppl. 1): 5-41.

23 Guenther PM, DeMaio TJ, Ingwersen LA. The multiple-pass approach for the 24-hour recall in The Continuing Survey of Food Intakes by Individuals (CSFII) 1994-96. In: Willett WC, Sampson L, eds. Second International Conference on Dietary Assessment Methods. Proceedings of a Symposium held in Boston, MA, January 22-24, 1995 [Special Issue]. Am. J. Clin. Nutr. 1997; 65(45): 13165.

24 Cypel YS, Tippett KS, eds. Design and Operation: The Continuing Survey of Food Intakes and the Diet and Health Knowledge Survey 1994-96. Nationwide Food Surveys Report. Washington, DC: US Department of Agriculture, Agricultural Research Service, 1998.

25 Australia New Zealand Food Authority. Composition of Foods Australia. Vols. 1-7. Canberra: Australian Government Publishing Service, 1989.

26 World Health Organization (WHO). Physical Status: The Use and Interpretation of Anthropometry. Report of a WHO Expert Committee. WHO Technical Report Series No. 854. Geneva: WHO, 1995.

27 Australian Bureau of Statistics (ABS). Year Book Australia 1995. Publication No. 77. Canberra: ABS, 1996.

28 Australian Bureau of Statistics (ABS). 1989-1990 National Health Survey, Health Risk Factors, Australia. Canberra: ABS, 1992.

29 Bennett SA, Magnus P. Trends in cardiovascular risk factors in Australia: results from the National Heart Foundation's Risk Factor Prevalence Study, 1980-1989. Med.J. Aust. 1994; 161: 519-27.

30 Commonwealth Department of Health in collaboration with the National Heart Foundation. National Dietary Survey of Adults: 1983. No 1 Foods consumed. Canberra: Australian Government Publishing Service, 1986.

31 Commonwealth Department of Health in collaboration with the National Heart Foundation. National Dietary Survey of Adults: 1983. No 2 Nutrient intakes. Canberra: Australian Government Publishing Service, 1987.

32 Australian Bureau of Statistics and Department of Health and Family Services. National Nutrition Survey, Selected Highlights, Australia 1995. ABS Catalogue No. 4802.0. Canberra: Commonwealth of Australia, 1997.

33 Australian Bureau of Statistics and Department of Health and Family Services. National Nutrition Survey - Foods eaten, Australia 1995. ABS Catalogue No. 4804.0. Canberra: Commonwealth of Australia, 1997.

\section{Appendix - Complete listing of food source categories}

Shop (such as supermarket, corner shop and chemist shop), speciality shop (such as delicatessen), food stall or product market

Restaurant, café, cafeteria, takeaway/pizza/fast food place Bar, tavern, hotel, club, pub

School canteen

Vending machine

Child-care centre, family day care home, adult day care centre

Soup kitchen, refuge, community service organisation Meals on wheels

Grown or caught by you or someone you know

Someone else, gift

Mail order purchase

Workplace tea trolley, tea club

Residential dining facility

Other (specify)

Don't know 